\title{
Senior High School Students' Conception of Learning Biology in Relation to Self-Regulated Learning Strategies: Their Impact on Students' Academic Performance
}

\author{
Mascardo, Maria Jida C., Lasala, Paula Belle S., Lazarte, Renaire Francis A.
}

\begin{abstract}
This study aims to identify the relationship between the grade 12 senior high school students' conception of learning biology and their self-regulated learning strategies and the impact of these variables on the academic performance of the students. Two sets of questionnaires - the Conception of Learning Biology questionnaire and the Self-Regulated Learning Strategies questionnaire - were administered to students in the different public secondary schools in Cebu City whose schools offered Science, Technology, Engineering and Mathematics (STEM) strand in the Senior High School curriculum. This research used exploratory factor analysis to analyze the data. The results reveal that there is a significant positive relationship among all the variables in the conception of learning biology and all factors in self-regulated strategies of senior high school students. The data further reveal that there is a significant positive relationship between the students' academic performance and one of the factors of selfregulated learning strategies. The results of the study have implications on the teaching of biology particularly on understanding student's conception of learning and their self-regulated learning strategies in order to achieve better academic outcomes. It is recommended for teachers to make necessary interventions in order to encourage students to develop advanced order conceptions of learning and higher order self-regulated learning strategies that would help them attain high academic performance.
\end{abstract}

Keywords:- Conceptions of Learning, Self-Regulated Learning.

\section{INTRODUCTION}

The objective of research in education is to give considerations that will guarantee a viable and proficient exchange of learning to serve both the instructors and students. In instructing science, the test of teaching students is to create long-lasting learning abilities that will make students fit for basic reasoning and critical thinking. (Dochy et al., 1999; Asikainen et al., 2013). Research in Education attempt to investigate and comprehend the learning procedure - how students obtain information and aptitudes. They investigate the nature and convictions of students concerning the conceptions of learning, learning methodologies, and execution (Duell and Schommer, 2001; Tsai, 2004). Prior research has demonstrated proof that people differ in their conceptions of learning and are significantly affected by complex factors such as learner's profile, intellectual, inspirational and social components (Purdie et al. 1996; Yang \& Tsai, 2010; Alamdarloo et al., 2013; Sadi et al. 2017).

Students' conception of learning is a coherent arrangement of information and one's convictions and comprehension of the idea of learning and instructive activities (Chiou\& Liang, 2012). It is constructed from a student's understanding and is, accordingly, a domaindependent task. Numerous researches concentrating on students' conception of learning have shown that students subjectively differ in their learning conceptions (Purdie\& Hattie, 2002). It is an established idea that students possess distinctive conceptions of learning in various subject areas. In technical disciplines, especially in biology or physics, students' conception of learning may reveal various systems. Consequently, for this research, it is crucial to concentrate on one area.

The conception of learning and self-regulated learning techniques are important catalysts to positive academic performance. The conception of learning has been generally examined. However, a study of the same purpose directed towards Filipino senior high school students is yet to be done. Although there have been numerous examinations researching students' development of learning, not many of these have concentration on self-regulated learning systems in a specific content domain. This study investigated the students' conception of learning Biology and its connection to self-regulated learning procedures in Biology. Given that students procure domain-specific views on learning (Buehl \& Alexander, 2001; Tsai, 2004), it is necessary for educators to recognize students' methods and conceptions of learning Biology.

In the conception of learning, students possess distinctive methods in meeting their learning objectives. The common method of describing the student's approaches is accurately identifying their continuous learning process (J. Biggs, D. Kember, and D. Leung 2001). Students study distinctive scholastic subjects in different ways; in this manner, the students develop domain-specific dispositions in dealing with learning. Self-regulated learning technique is one of the strategies centered in this study. Self-regulated learning techniques may impact students' motivation, conduct, and execution, their understanding of the learning 
process and results. These will consequently influence their self-regulation, producing a cyclic system. Accordingly, this study is directed to exploring the connection between conception of learning and self-regulated learning methodologies and how they impact academic performance.

\section{CONCEPTUAL FRAMEWORK}

Figure 1 shows the conceptual framework of the study. The study aims to examine the relationship of the senior high school students' conceptions of learning Biology and their self-regulated learning strategies as well as the effect of the two variables on students' academic performance. The independent variables are the students' conceptions of learning and their self-regulated learning strategies while the dependent variable is the students' academic performance.

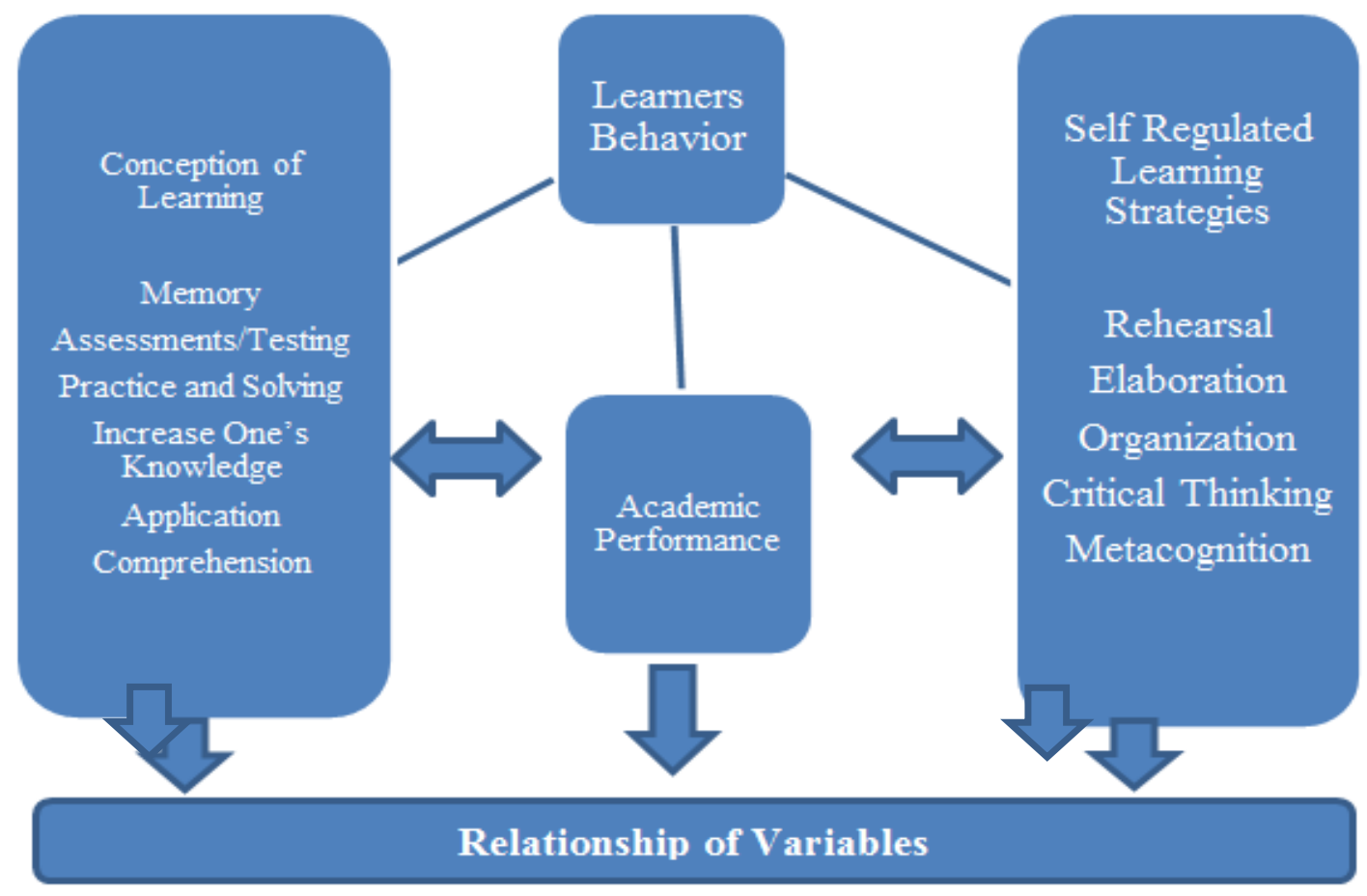

Fig 1:- Conceptual Framework of the Study

Conceptions of Learning include memory, assessment or testing, practice and solving, increase one's knowledge, application, and comprehension. Memory or memorizing is retaining one's information in Biology and recalling it when necessary while assessment or testing is learning Biology as preparing for examinations and getting high scores in the subject. Calculating and practice is learning by solving problems like that of answering quantitative calculations, investigating scientific experiments, and manipulating of formulae. Learning Biology as to increase one's knowledge is simply increasing Biology knowledge aside from the prior learning obtained whereas applying is done through creating explanations of any unknown questions, and phenomena. Lastly, comprehension is achieving factual perceptions and forming links between concepts.

This study adapted 2017 Pintrich's model of SelfRegulated Learning Strategies which have five (5) categories namely: rehearsal, elaboration, organization, critical thinking, and metacognition. These categories affect student's progress regarding its performance in Biology subject. Rehearsal learning strategy is listing, naming the items from the list and reciting the concepts for several times until mastered. This type of strategy is probable for a short period of time with simple tasks and remembering memory rather than gaining of new idea in long-term memory. Rehearsal is anticipated to influence the encoding processes and the attention span of the students, but does not appear to be helpful to students in constructing internal connections with prior knowledge. Elaboration strategy is storing information into long-term memory through creating internal connections between the items to be learned. This type of regulation includes summarizing, paraphrasing, note-taking, and making analogies out of the topic. Through elaboration, the learner integrates new procedures with past knowledge. Organization is another element that allows the learners to select appropriate information, and to generate the systems from the learning. In addition, organizing comprises forming outlines, and selecting the main ideas in long paragraphs or any reading passages. Critical thinking refers to the degree to which students apply previous knowledge to new situations in solving problems, and in making evaluations as to standards of excellence. The last category is metacognition that refers to the control of cognition, and awareness of knowledge. This study absorbed the metacognition of the MSLQ on the control of self-regulation. Metacognitive 
self-regulation activities have three key processes: plan, monitor, and regulate the learning. Planning involves goal setting, and analyzing of tasks in activating pertinent aspects of previous information to make organization and comprehension easier. In monitoring, a person tracks his attention as he reads something by means of questioning, and self-testing. These steps assist learners to understand the material and integrate it to their past cognitive thoughts. Finally, regulating or simply retention is an act of continuously adjusting to one's cognitive procedures. This motion is assumed to assist learners in checking, correcting behavior, and improving tasks.

\section{Statement of the Problem}

This study is designed to investigate the relationship of conception of learning, self-regulation learning strategy and students' academic performance in biology course among senior high school students from public schools.

Specifically, this study will answer the following questions:

- What is the respondents' level of conception of learning biology in the following:

$\checkmark$ Memory

$\checkmark$ Assessments/Testing

$\checkmark$ Practice and Solving

$\checkmark$ Increase One's Knowledge

$\checkmark$ Application

$\checkmark$ Comprehension

- What is the respondent's self-regulation strategy to learning biology:

$\checkmark$ Receiving

$\checkmark$ Evaluating

$\checkmark$ Triggering

$\checkmark$ Searching

$\checkmark$ Formulating

$\checkmark$ Implementing

$\checkmark$ Assessing

- What is the level of academic performance of respondents' in biology course?

- Is there any substantial relationship among conception of learning, self-regulation learning strategy and student's academic performance?

\section{RESEARCH DESIGN AND METHODS}

\section{$>$ Research Design}

This study utilized a descriptive correlation research design as it aimed to identify the relationship among the three variables: 1.) the grade 12 Senior High School (SHS) students' conception of learning biology; 2.) the students' self-regulated learning strategies; and 3.) the students' academic performance.

\section{$>$ Research Environment}

The study was implemented in nine selected public senior high schools in Cebu City offering STEM strand particularly Apas National High School, Cebu City Science High School, Don Carlos Gothong National High School, Don Sergio Osmena Memorial National High School, Don Vicente Rama Memorial National High School, Mabolo National High School, Ramon Duterte Memorial National High School, Talamban National High School, and Tisa National High School.

\section{$>$ Respondents}

This study had a total respondents of 377 Grade 12 senior high school students who were taking the Science, Technology Engineering, and Mathematics (STEM) strand at different public secondary schools in Cebu City. These students were taking Biology as one of the science subjects in senior high school. Slovin's formula was used in determining the sample size of the study. In the selection of the research participants, systematic random sampling method was used. From the advisers' class records, the researchers randomly selected the even-numbered names of students.

\section{$>$ Research Instrument}

This study used survey questionnaires to gather the necessary data. The respondents were asked to answer two sets of survey questionnaires - one on the conception of learning biology with thirty-one statements and another one on the self-regulation strategies with 31 statements, respectively.

The questionnaires were adapted from Pintrich's Model of Conceptions of Learning and Motivated Strategies for Learning Questionnaires. Thirty-one (31) Self-regulated Learning segments in the questionnaire were all used while some of the statements in the questionnaire for Conceptions of Learning were modified in order to suit the needs of the study. The technical panel composed of the Biology education specialist, English communicator and grammar specialist, and Education program supervisor for senior high school STEM strand reviewed the survey questionnaires and their suggestions and comments were integrated in the final draft. The questionnaires were pilot tested for validity and reliability prior to the actual conduct of the survey.

This tool adopted a 7-point Likert scale to quantify the data. The respondents answered the survey by placing a check mark on the box that corresponded to their answer for each item. 
ISSN No:-2456-2165

\begin{tabular}{|c|c|c|c|}
\hline Scale & Range & Description & Qualitative Interpretation \\
\hline 7 & $6.11-7.00$ & Completely Agree & Extremely Positive \\
\hline 6 & $5.26-6.10$ & Mostly Agree & Highly Positive \\
\hline 5 & $4.41-5.25$ & Slightly Agree & Positive \\
\hline 4 & $3.56-4.40$ & Undecided & Fair \\
\hline 3 & $2.71-3.55$ & Slightly Disagree & Negative \\
\hline 2 & $1.88-2.70$ & Mostly Disagree & Highly Negative \\
\hline 1 & $1.00-1.85$ & Completely Disagree & Extremely Negative \\
\hline
\end{tabular}

Table 1:- The scoring guide for conceptions of learning biology and self-regulated learning strategies

The academic performance of the respondents was based on their grade in the biology course for the $2^{\text {nd }}$ quarter. The grades were interpreted based on DepEd Order No. 08 series 2015. The performance of each student was rated according to his/her level of proficiency with the following equivalents: 90-100 - Outstanding, 85-89 - Very Satisfactory, 80-84 - Satisfactory, 75-79 - Fairly Satisfactory, and below 75 - academic performance did not meet expectations.

\section{Data Gathering Procedure}

The researchers sought the permission of the Office of the Schools Division Superintendent and the school heads of the participating schools to conduct the survey. The researchers then personally conducted and managed the actual survey among the identified public schools. The respondents were to complete the two survey instruments in one sitting with no time limit. The respondents were assured of the confidentiality of their responses. The gathered data were organized and tabulated for statistical computation and analysis.

\section{Statistical Treatment}

The normality of the data sets was analyzed based on the assumption of normality and linearity using the Kolmogorov-Smirnov normality test. Weighted mean and standard deviation were used to describe the data on students' conceptions of learning biology and self-regulated learning strategy. Pearson Product Moment of Correlation (Pearson $r$ ) was used to determine the magnitude of the relationships among the variables in this study. The correlation probability value ( $\mathrm{p}$-value) was computed to establish the significance of the relationship.

\section{RESULTS AND DISCUSSION}

\begin{tabular}{|c|c|c|c|}
\hline Component & Weighted Mean & Standard deviation & Interpretation \\
\hline Memorizing & 5.1668 & 0.9634 & Positive \\
\hline Testing & 4.4403 & 1.1133 & Positive \\
\hline Calculating and Practicing & 5.6820 & 0.8711 & Highly Positive (+) \\
\hline Increasing One's Knowledge & 5.6361 & 0.9759 & Highly Positive \\
\hline Applying & 5.3984 & 0.9556 & Highly Positive \\
\hline Understanding & 5.6138 & 0.9446 & Highly Positive \\
\hline
\end{tabular}

Table 2:- Descriptive statistics of students' conception of learning strategies in biology

Approach positive (+) highest value

Students can work and learn in various mechanisms and are not limited to a surface approach or a profound approach. Students can do adjustments shifting between the different schemes of learning based on their perceived circumstances. Similarly, they have their own views of learning that can be applied in a specific context, thus, students who have memorizing, assessments, practice and solving conceptions are more into surface learning approach not reconsidering the demands of more knowledge. On the other hand, students who recognize high conceptions of learning are capable of adopting a weightier approach to acquiring knowledge and will make use of it as a necessity.

Table 2 shows the descriptive statistics of students' conception of learning strategies in biology. Data reveal that, among the factors of conception of learning, Calculating and Practicing obtained the highest mean value of 5.6820 interpreted as Highly Positive (+). Lee et al. in 2008 categorized calculation and practice as low level of conception of learning. Memorizing and Testing obtained the lowest mean values of 5.1668 and 4.4403, respectively interpreted as Positive. Students who demonstrate calculating and practicing as conception of learning, are most likely motivated to perform well in science examinations which is a major indicator of student progress (Lee, Johanson \& Tsai, 2008). In addition to this, Tsai identifies one category of the conception of learning like calculating and practicing as unique to science and which reveals specific views about the nature of science that involves many calculations and problem-solving (Tsai, 2004).

As to the other factors of conception of learning, Increasing one's knowledge, Understanding, and Applying obtained mean values of 5.6361, 5.6138 and 5.3984, respectively which are all interpreted as Positive. The data implied that students prefer to view learning biology in a higher level of perspective in the conception of learning rather than in the lower level. Moreover, Lee et al. (2008) 
categorized these three factors as the high level of the conception of learning as confirmed by the study of Lin, Tsai and Liang (2012). The high-level conception of learning involves learning processes that transform students' perceived information into a meaningful and holistic outcome (Shen et al. 2016). The data showed remarkable result since the views of the students on the conception of learning biology focus on the understanding of the concept and an interest in the learned concepts.

\begin{tabular}{|c|c|c|c|}
\hline Component & Mean & Standard deviation & Interpretation \\
\hline Rehearsal & 5.6054 & 0.9045 & Highly Positive (+) \\
\hline Elaboration & 5.4611 & 0.8833 & Highly Positive \\
\hline Organization & 5.4350 & 0.9459 & Highly Positive \\
\hline Critical Thinking & 5.2955 & 0.8560 & Highly Positive \\
\hline Metacognition & 5.2942 & 0.7448 & Highly Positive (-) \\
\hline
\end{tabular}

Positive (+) highest value

Negative (-) lowest value

Table 3:- Descriptive statistics of students' self-regulating strategies in learning biology

Table 3 shows the descriptive statistics of students' self-regulated strategies in learning biology.

Data reveal that Rehearsal obtained the highest mean value of 5.6054 interpreted as Highly Positive (+) followed by Elaboration and Organization with mean values of 5.4611 and 5.4350, respectively. These three factors Rehearsal, Elaboration and Organization were categorized by Pintrich and De Groot in 1990 as cognitive selfregulated learning strategies. On the other hand, Metacognition obtained the lowest mean value of 5.2942 interpreted as Highly Positive (-).
The results show that students prefer Rehearsal as their primary self-regulating strategy which can be associated with paying attention to the lesson, selecting and retaining essential information in the memory (Pintrich, 1999). Moreover, Rehearsal, Elaboration and Organizational cognitive self-regulating strategies are related to recalling and understanding information in class discussions (Weinstein \& Mayer, 1986). Students prefer to rehearse continuously for them to learn the concepts in their biology lessons and get high scores in the exams (Ozcelik\& Yay, 2014). This learning strategy is used by students when learning information during discussions which need to be retained in mind (Pintrich, 1999). Student's self-regulated strategies are restricted only to the extent that they monitored and controlled study strategies that are related to rehearsal, elaboration, and organization (Wolster, 1998).

\begin{tabular}{|c|c|c|c|}
\hline Grade Component & $\mathrm{N}$ & Percentage (\%) & Descriptor \\
\hline $90-100$ & 203 & 53.85 & Outstanding \\
\hline $85-89$ & 108 & 28.65 & Very Satisfactory \\
\hline $80-84$ & 66 & 0 & Satisfactory \\
\hline $75-79$ & 0 & 0 & Dirly Satisfactory not Meet \\
\hline Below 75 & 0 & 17.51 & Expectations \\
\hline Total & 377 & & Very Satisfactory \\
\hline
\end{tabular}

Table 4:- Frequency Distribution of students' grade in Biology

Table 4 shows the frequency distribution of students' grades in Biology. As shown, 53.85\% of the total population obtained grades within the $90-100 \%$ range or a rating of Outstanding. This indicates that students were able to successfully cope with the standards of a science high school. 


\begin{tabular}{|c|c|c|c|c|c|c|c|}
\hline & 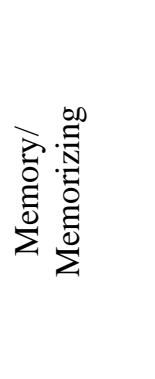 & 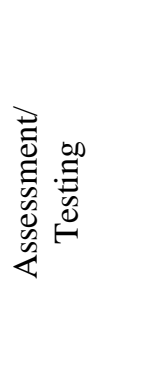 & 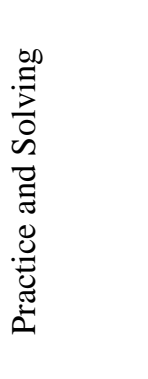 & 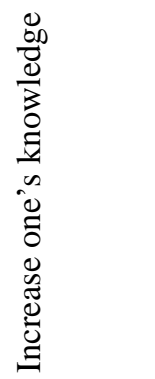 & 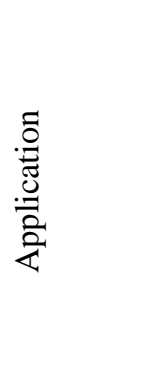 & 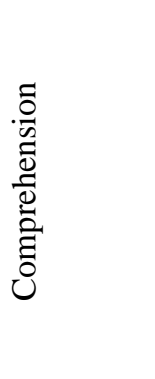 & 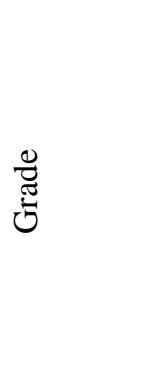 \\
\hline Rehearsal & $0.174 *$ & $0.115^{*}$ & $0.152 *$ & $0.254 *$ & $0.221 *$ & $0.261 *$ & $0.101 *$ \\
\hline Elaboration & $0.233^{*}$ & $0.112^{*}$ & $0.213^{*}$ & $0.198 *$ & $0.312 *$ & $0.294^{*}$ & 0.093 \\
\hline Organization & $0.128^{*}$ & $0.137^{*}$ & $0.237 *$ & $0.217 *$ & $0.283^{*}$ & $0.258^{*}$ & 0.070 \\
\hline Critical thinking & $0.237^{*}$ & $0.127^{*}$ & $0.229 *$ & $0.256^{*}$ & $0.312 *$ & $0.318^{*}$ & -0.022 \\
\hline Metacognition & $0.220^{*}$ & $0.129 *$ & $0.284 *$ & $0.333^{*}$ & $0.378 *$ & $0.363^{*}$ & -0.036 \\
\hline Grade & -0.046 & $-0.256^{*}$ & 0.094 & $0.149 *$ & $0.123^{*}$ & $0.162 *$ & \\
\hline
\end{tabular}

*Correlation is significant at the 0.05 level

Table 5:- Correlation coefficient of the variables: the conception of learning, self-regulated learning strategies and students' academic performance

Table 5 presents the correlation coefficient of the three variables of the study: the conception of learning biology, the self-regulated learning strategies and students' academic performance. The Pearson correlation coefficient was used to analyze the relationship among these three variables. The results reveal that there is a significant positive relationship between the conception of learning biology and the students' self-regulated learning strategies.

With regards to students' academic performance and conception of learning, there is a significant positive relationship between these two variables; however, this relationship is not significant among these factors: increases one's knowledge, applying and understanding. These findings are in line with the radical change of the aim of the senior high school STEM track in educating students that will develop and practice knowledge, skills, and understanding regarding science, specifically biology concepts. According to Sadi in 2016, to achieve these aims, it is very necessary for students to have higher-level conceptions of learning biology and active participation in class discussions and become a life-long learner.

On the other hand, there is a significant negative relationship $(\mathrm{r}=-0.256, \mathrm{p}<0.05)$ between students' academic performance and testing. The students still obtained Satisfactory rating even though their focus was not much on testing or examination. This result implies that student's beliefs on testing have nothing to do with their academic performance. The result also suggests that students' preparation for the assessment in learning biology is focused more on understanding and improving skills instead of merely passing the exams. However, some factors may influence students' beliefs on testing. For one, it has been the culture of Philippine education to give more importance to getting high marks in examinations, thus students study mainly to obtain good grades.

With regards to the relationship between students' academic performance and their self-regulated learning strategies, data reveal that there is a significant positive correlation between academic attainment and Rehearsal. This result implies that students spend much more time in using Rehearsal as a self-regulated learning strategy which for them is a better way to achieve good grades. According to Weinstein et al. 2000, a Rehearsal strategy involves repetition of information, content learning tasks like copying, taking notes, underlining and marking text. Weinstein and other researchers pointed out that rehearsal strategy is practiced by students who are performanceoriented and are motivated by extrinsic factors such grades (Pintrich\& De Groot, 1990; Heyman\&Dweck, 1992; Weinstein et al., 2000).

\section{CONCLUSION AND IMPLICATIONS}

Statistical data analysis reveals a positive correlation between students' conceptions of learning and academic achievement. High-order conceptions of learning are encouraged among SHS students. This develops the regulation of learning which improves academic performance. Although students perceive the required level of understanding to excel in Biology, their most preferred conception of learning is practicing and calculating. The results also confirm that the students prefer using Rehearsal as a more effective self-regulated learning strategy in achieving good grades as opposed to metacognition and deeper critical thinking. It is a special contradicting case of the conceptions of learning and the self-regulation strategy of senior high school students where they highly perceive Biology yet lowly regulate the ideas learned in Biology. Hence, the results of the study validate the importance of understanding students' conceptions of learning and selfregulated strategies to achieve better academic outcomes. In this light, the results might be considered by both researchers and teachers in identifying the students' conceptions of learning and their learning strategies reliably. This would give implications to the development of the curriculum in directing teacher's instructional strategies utilizing the conceptions of learning in Biology. 


\section{RECOMMENDATIONS}

The researchers recommend that to develop academic excellence in students, teachers should initiate necessary interventions to promote higher-order conceptions of learning Biology and enhance students' self-regulated learning strategies which would result in positive learning outcomes. The study was conducted to STEM students in public high schools; therefore, future studies may include students in both public and private high schools and also other strands or tracks with science subjects. As observed in the study, the correlation of learning conceptions, learning strategies, and academic performance can be utilized for different subjects such as chemistry, physics, or other areas of focus.

\section{REFERENCES}

[1]. Alamdarloo, G. ,Moradi, S. \&Dehshiri, G. (2013). The Relationship between students' conceptions of learning and their academic achievement. Psychology, 4, 44-49. doi: 10.4236/psych.2013.41006.

[2]. Asikainen, H., Virtanen, V., Parpala, A., \&LindblomYlänne, S. (2013). Understanding the variation in bioscience students' conceptions of learning in the 21 st century. International Journal of Educational Research, 62, 36-42.

[3]. Buehl, M. M., \& Alexander, P. A. (2001).Beliefs about academic knowledge. Educational Psychology Review, 13(4), 385-418.

[4]. Biggs, J.B. Kember, D. \& Leung, D.Y.P. (2001). The Revised Two Factor Study Process Questionnaire: RSPQ-2F. British Journal of Educational Psychology $71,133-149$.

[5]. Chiou, G.L. \& Liang, J.C. (2012) Exploring the Structure of Science Self-efficacy: A model Built on High School Students Conception of Learning and Approaches to Learning in Science. The Asia- Pacific Education Researcher, Vol 21:1, pp 83 - 91.

[6]. Dochy, F., Segers, M., \&Buehl, M. M. (1999). The relation between assessment practices and outcomes of studies: The case of research on prior knowledge. Review of Educational Research, 69(2), 145-186.

[7]. Duell, O.K. and Schommer, M. (2001).Measures of people's beliefs about knowledge andlearning.Educational Psychology Review, 13, 419 449.

[8]. Lee, M-H., Johanson, R. E., \& Tsai, C-C. (2008). Exploring Taiwanese high school students' conceptions of and approaches to learning science through a structural equation modeling analysis. Science Education, 92(2), 191-220. doi: 10.1002/sce.20245.

[9]. Pintrich, P. R. (1999). The role of motivation in promoting and sustaining self-regulated learning. International journal of educational research, 31(6), 459-470.
[10]. Purdie, N., Hattie, J., \& Douglas, G. (1996). Student conceptions of learning and their use of self-regulated learning strategies: A cross-cultural comparison. Journal of educational psychology, 88(1), 87.

[11]. Sadi, Ö.,\&Dağyar, M. (2017). Relational Analysis of High School Students' Cognitive Self-Regulated Learning Strategies and Conceptions of Learning Biology. Eurasia Journal of Mathematics, Science \& Technology Education, 13(6), 1701-1722.

[12]. Tsai, C. C. (2004). Conceptions of learning science among high school students in Taiwan: A phenomenographic analysis. International Journal of Science Education, 26(14), 1733-1750.

[13]. Yang, Y.F., \& Tsai, C.C. (2010). Conceptions of and approaches to learning through online peerassessment. Learning and Instruction, 20(1), 72-83.

[14]. Shen, K. M., Lee, M. H., Tsai, C. C., \& Chang, C. Y. (2016). Undergraduate students' earth science learning: relationships among conceptions, approaches, and learning self-efficacy in Taiwan. International Journal of Science Education, 38(9), 1527-1547.

[15]. Lee, M. H., Johanson, R. E., \& Tsai, C. C. (2008). Exploring Taiwanese high school students' conceptions of and approaches to learning science through a structural equation modeling analysis. Science Education, 92(2), 191-220.

[16]. Pintrich, P. R. (1999). The role of motivation in promoting and sustaining self-regulated learning. International Journal of Educational Research, 31, 459-470.

[17]. Weinstein, C. E., Husman, J., \&Dierking, D. R. (2000).Self-regulation interventions with a focus on learning strategies.In Handbook of self-regulation (pp. 727-747).

[18]. Pintrich, P. R., \& De Groot, E. V. (1990).Motivational and self-regulated learning components of classroom academic performance.Journal of educational psychology, 82(1), 33.

[19]. Heyman, G. D., \&Dweck, C. S. (1992). Achievement goals and intrinsic motivation: Their relation and their role in adaptive motivation. Motivation and emotion, 16(3), 231-247.

[20]. Ozcelik, H., \& Yay, N. A. (2014).University candidates overview the departments of biology (example of Isparta). SDU Journal of Science (EJournal), 9(1), 56-94. 